\title{
Infrared spectroscopic analysis of staghorn calculi obtained after open renal surgery in a urology unit of Sri Lanka
}

K S N Wijayarathna ${ }^{1}$, G G A P Weerasingha ${ }^{2}$, A S Weligamage ${ }^{1}$, R Chandrajith $^{2}$, A M Abeygunasekera ${ }^{1}$

(Index words: staghorn stones, composition, Sri Lanka, FTIR spectroscopy, urolithiasis)

\begin{abstract}
The composition of renal stones varies widely among populations. The aim of our study was to determine the composition of staghorn renal stones using Fourier transform infrared (FTIR) spectroscopy in a cohort of Sri Lankan patients. Forty two staghorn calculi removed from kidneys of adult patients during open surgery were analysed. There were 32 men. Nineteen (45\%) were calcium oxalate monohydrate (whewellite) stones. Stones containing a mixture of calcium oxalate and calcium hydroxyl phosphate (apatite) were found in 16 $(38 \%)$. Only $4(10 \%)$ staghorn calculi were coposed of struvite. Three $(7 \%)$ were uric acid stones. So most staghorn renal stones in Sri Lanka are calcium oxalate. Contrary to the traditional view based on studies done in the western world, only $10 \%$ of staghorn calculi removed from patients in Sri Lanka are struvite or infection stones. This could be the reason for kidneys with staghorn calculi in Sri Lanka to retain their function.
\end{abstract}

Ceylon Medical Journal 2016; 61: 74-76

DOI: http://doi.org/10.4038/cmj.v61i2.8288

\section{Introduction}

Urolithisasis is a common problem worldwide. Sri Lanka belongs to the stone belt in Asia which includes India, Pakistan and Southern China [1]. The composition of renal stones has a direct impact on treatment, secondary prevention and prognostication [2]. Calcium oxalate monohydrate stones are hard and resistant to extracorporeal shock wave lithotripsy [3]. Struvite calculi are associated with destruction of renal tissues and more infective complications postoperatively [4]. The composition of stones varies widely among populations $[1,5]$. Even in the same country stone composition can change according to the geographical locality [6].
Therefore it is useful to know the pattern of calculi in a country and region when planning treatment.

A stone that occupies the renal pelvis and extends into at least two major calyceal systems is considered a staghorn calculus [7]. Commonly the stone fills the whole pelvi-calyceal system giving the appearance of a stag's horn. Traditionally staghorn calculi are associated with infection stones made up of struvite [8,9]. Struvite is the mineral name for magnesium ammonium phosphate $\left(\mathrm{MgNH}_{4} \mathrm{PO}_{4} \cdot 6 \mathrm{H}_{2} \mathrm{O}\right)$ [10]. Alkaline urine formed by urea splitting bacteria promotes the formation of struvite.

A study done in Sri Lanka has shown that the composition of Sri Lankan staghorn calculi is likely to be different from that described in the literature based on studies done in the western world [7]. This observation was based on indirect evidence initially [7] and was confirmed by chemical analysis of renal stones [11]. Chemical analysis of stones does not identify crystal types and is a deficiency of the method [12]. Of the many methods available for urinary stone analysis, Fourier transform infrared (FTIR) spectroscopy is the most widely used in clinical settings in the developed world [12]. FTIR spectroscopy is easy, accurate and can be well adapted to routine laboratories. There are no published studies based on FTIR spectroscopic analysis of renal stones in Sri Lanka.

The objective of our study was to determine the composition of staghorn renal stones obtained after open renal surgery in a cohort of Sri Lankan patients using the FTIR method.

\section{Methods}

All adult patients who underwent open (pyelolithotomy and nephrolithotomy) surgery for removal of staghorn renal stones in a urology unit of a tertiary care

${ }^{1}$ Urology Unit, Colombo South Teaching Hospital, Sri Lanka, ${ }^{2}$ Department of Geology, Faculty of Science, University of Peradeniya, Sri Lanka.

Correspondence: AMA, e-mail: <amabey@sltnet.lk>. Received 13 January 2016.

This is an open-access article distributed under the terms of the Creative Commons Attribution License, which permits unrestricted use, distribution, and reproduction in any medium, provided the original author and source are credited. 
hospital over one year were included in the study. The study period was from 1 July 2013 to 30 June 2014. A stone that occupies the renal pelvis and extends into at least two major calyceal systems was considered a staghorn calculus. Demographic and relevant clinical data were recorded. All patients with a serum creatinine less than $150 \mu \mathrm{mol} / \mathrm{l}$ had a CT urogram in addition to routine investigations before major surgery. Whenever CT urogram facilities were not available for technical problems of the CT scanner, intravenous urogram (IVU) was done as the contrast imaging study. Those who had nonfunctioning kidneys on CT urogram or IVU, had a DTPA renogram to assess split function of kidneys. All stones were analysed by Fourier transform infrared spectroscopy. The FTIR measurements were done using Thermo Scientific Nicollet is50 FTIR spectrometer available at the Department of Soil Science, University of Peradeniya. Approval for the study was obtained from the Ethics Review Committee of the Institute.

\section{Results}

The study cohort included 42 patients. There were $32(76 \%)$ men $(\mathrm{M}: \mathrm{F}=3 \cdot 2: 1)$. Median age was 50 (range: 2676) years. CT urogram was performed in 39 patients and two patients had IVU. One patient who had elevated serum creatinine $(289 \mu \mathrm{mol} / 1)$ did not have a contrast study. Thirty eight $(90 \%)$ patients had a functioning kidney in the CT urogram or IVU. The three patients who had non-excreting kidneys had $15 \%, 19 \%$ and $27 \%$ function in the DTPA renogram. Hence those patients also underwent removal of stones rather than nephrectomy.

Two patients had preliminary percutaneous nephrostomy (PCN) before definitive surgery. One of them had a pyonephrosis secondary to obstruction by the stone, and the other had a serum creatinine of $289 \mu \mathrm{mol} / 1$ because of bilateral renal stones. Hence he had a preliminary percutaneous nephrostomy (PCN). One staghorn calculus was radiolucent. Other 41 stones were radio-opaque.

Pyelolithotomy or extended pyelolithotomy was done in 30 patients. Nephro-pyelolithotomy was done in 11 patients. One patient had a concomitant cystic mass with solid areas in the affected kidney. He had a nephrectomy as there was a possibility of a malignancy. Six patients who had intrarenal pelvis and repair of the pyelotomy was difficult, had insertion of a double $\mathrm{J}$ ureteric stent at the time of surgery.

Six patients had Clavien grade $\geq 2$ complications during the postoperative period [13]. These included two patients with surgical site infection, two patients who required post operative blood transfusion, one patient who underwent ureteric stenting for persistent urine leak two weeks after surgery, and one patient who developed a respiratory tract infection requiring stay in the intensive care unit.
The commonest type of stones was calcium oxalate monohydrate (whewellite) (45\%) followed by stones containing a mixture of calcium oxalate and apatite (38\%) (Table). Apatite is the mineral name for calcium hydroxyl phosphate, also known as tri-calcium phosphate $\left\{\mathrm{Ca}_{10}\left(\mathrm{PO}_{4}\right)_{6}(\mathrm{OH})_{2}\right\}$. Struvite calculi constituted only $10 \%$ of the stones.

\section{Discussion}

This study describes the composition of renal stones determined using infrared spectroscopic analysis in a group of patients from Sri Lanka. According to the study calcium oxalate monohydrate stones remain the commonest type of staghorn calculi in Sri Lankan patients. Mixed stones containing calcium oxalate and calcium hydroxyl phosphate (apatite) are the second most common $(38 \%)$ variety. Mixed stones were less common (19\%) in a study done previously in the same unit where analysis was done using chemical methods [11]. In India calcium oxalate stones constitute $90 \%$ of staghorn calculi [1]. In USA calcium oxalate stones are uncommon (4\%) among staghorn calculi [8]. In Iran uric acid stones constitute $17.7 \%$ of staghorn calculi, compared to $11.5 \%$ in USA, $1 \%$ in India and $7 \%$ in our study $[1,4,8]$. In India mixed stones containing calcium oxalate and apatite stones constitute only $4 \%$ of staghorn calculi compared to $38 \%$ in our study [1]. In Japan struvite calculi constitute $32 \%$ of staghorn stones [14]. Second most common type (22\%) of staghorn calculi in Japan is calcium oxalate and calcium phosphate stones, as in our study. In West Asian countries consumption of nuts rich in uric acid is high. Rice based diets commonly consumed in South Asian countries provides an acidic milieu to urine, favouring calcium oxalate stone formation [1]. It has been shown that damage to renal tissues by oxalate stones is minimal compared to struvite stones [15]. This is probably the reason for kidneys with staghorn calculi in Sri Lanka to retain function despite having large calculi.

In conclusion, findings of this study confirm the changing composition of staghorn calculi in different countries. Staghorn calculi in Sri Lanka, like other kidney stones, are commoner in men. They consist mainly of calcium oxalate monohydrate and are not struvite or infection stones.

\section{Table. Distribution of different types of calculi among staghorn stones}

\begin{tabular}{lc}
\hline Stone type & Number $(\%)$ \\
\hline Calcium oxalate monohydrate & $19(45)$ \\
Calcium oxalate and Apatite & $16(38)$ \\
Struvite & $4(10)$ \\
Uric acid & $3(7)$ \\
Total & $42(100)$ \\
\hline
\end{tabular}




\section{Funding}

A grant from the University of Perdaeniya (RG/AF 2013/71/S) facilitated FTIR studies.

\section{Conflicts of interests}

There are no conflicts of interest.

\section{References}

1. Ansari MS, Guptha NP, Hemal AK, et al. Spectrum of stone composition: structural analysis of 1050 upper urinary tract calculi from Northern India. Int J Urol 2005; 12: $12-6$.

2. Blandy JP, Singh M. The case for a more aggressive approach to staghorn stones. J Urol 1976; 115: 505-6.

3. Dretler SP. Stone fragility: a therapeutic distinction. J Urol 1988; 139: 1124-34.

4. Hamid S, Zahra S, Behzad H, et al. Bacteriological study and structural composition of staghorn stones removed by the anatrophic nephrolithotomic procedure. Saudi J Kidney Dis Transpl 2013; 24: 418-23.

5. Abeygunasekera AM. Urinary stone disease in Sri Lanka. Ceylon Med J 2004; 49: 41-3.

6. Wumaner A, Keremu A, Wumaier D, Wang Q. Variation in urinary stone composition between adult uyghur and han patients with urolithiasis in xinjiang, China. Urology 2014; 84: $772-8$.

7. Abeygunasekera A, Nirupika H, Bulegoda H. An observational study of staghorn calculi in south Sri Lanka. Ceylon Med J 2002; 47: 115-6.

8. Davis VP, Mark SD, Duke H, Nicole ML. Changing composition of staghorn calculi. J Urol 2011; 186: 2285-90.

9. Preminger GM, Assimos DG, Lingeman JE, et al. Chapter 1: AUA guideline on management of staghorn calculi: diagnosis and treatment recommendations. J Urol 2005; 173: 1991-2000.

10. Gleeson MJ, Griffith DP. Struvite calculi. BJU 1993; 71: 503-11.

11. Kalana HPPG, Hunais MM, Suvendiran S, Palihakkara SD, Abeygunasekera AM. Chemical composition of kidney stones obtained from a cohort of Sri Lankan patients. Sri Lanka J Surg 2015; 33: 14-9.

12. Michel D, Dominique BC. Application of physical methods to kidney stones and Randall's plaque characterisation. In: Urolithiasis, Talai J J (ed); Springer-Verlag London 2012 doi 10.1007 1978-1-4471-4387-1_85.

13. Dindo D, Demartines N, Clavien PA. Classification of surgical complications: a new proposal with evaluation in a cohort of 6336 patients and results of a survey. Ann Surg 2004; 240: 205-13.

14. Akagashi K, Tanda H, Kato S, et al. Characteristics of patients with staghorn calculi in our experience. Int J Urol 2004; 11: 276-81.

15. Evan AP, Lingeman JE, Coe FL, et al. Crystal-associated nephropathy in patients with brushite nephrolithiasis. Kidney Int 2005; 67; 576-91. 